\title{
Comparative Assessment of Urban Flood Risks due to Urbanization and Climate Change in the Turnhout Valley of Belgium
}

\author{
Md. Shahabul Alam ${ }^{1}$, Patrick Willems ${ }^{2}$, Md. Masud Alam ${ }^{3}$ \\ ${ }^{1}$ Sub-Divisional Engineer, Bangladesh Water Development Board, BANGLADESH \\ ${ }^{2}$ Associate Professor, Department of Civil Engineering, Katholieke Universiteit Leuven, BELGIUM \\ ${ }^{3}$ Senior Scientific Officer, Water Resources Planning Organization, BANGLADESH
}

\begin{abstract}
The combined effect of urbanization and climate change on catchment runoff has been drawing attention in the recent years to assess the impact of climate change on urbanizing catchments. There has been extensive development of paved areas within the city of Turnhout in Belgium in combination with several modifications of the neighboring rivers. Moreover, the city authority has decided to encourage more densification of housing and industries within or next to the cores, which would lead to frequent overflows out of the existing combined sewer system. This combination leads to a faster flow of larger quantities of water which physically cannot be retained by the valleys over this region and thus causes increasingly frequent and harmful flood events affecting agricultural lands. The situation could be indisputably exacerbated under climate change scenarios. This study focuses on assessing the effects of urban development and climate change on flood risks in the downstream of Turnhout. For this study, a lumped conceptual hydrological model NAM was developed for generating runoff from the catchment. The CCI-HYDR perturbation tool, developed by Katholieke Universiteit Leuven, was applied to generate time series of future rainfall and evapotranspiration. The urban runoffs were obtained from the simulation of existing Info Works CS model under both current and climate change (A1B, A2, B1 and B2) scenarios. Rainfall-runoff was then uniformly distributed along the river reaches and urban runoff was applied as point source boundary conditions in the calibrated and validated MIKE 11 river flood model. Composite hydrographs with different return periods for all the boundary conditions were generated through extreme value analysis. The results show intensified and more frequent peak runoff resulting from combined effect of urbanization and climate change, in comparison to the individual effect of urbanization or climate change each. The increased peak runoff in the river due to heavy rainfall coinciding with development of paved surfaces within the city would lead to severe urban flooding when urbanization and climate change scenarios are accounted for.
\end{abstract}

Keywords: Urbanization, climate change, river flood model, urban runoff, flood risk, composite hydrograph 


\section{INTRODUCTION}

The hydrological system within a catchment is governed by a number of factors, climate change and urbanization being the two most important ones. Significant alteration in the volume and timing of runoff may be caused by the changes in either or both of these factors (Franczyk and Chang 2009). Many previous studies, assessing the impact of climate change on hydrology, found that there is a close association between stream flow variability and climate change. A significant impact of land use changes, especially caused by urbanization, on hydrology has been found in most of the previous studies (Tu 2009). However, only some limited studies have been conducted to analyze the combined effects of climate change and land use changes on stream flow (Tu, 2009, Franczyk and Chang 2009). Climate change projections for Belgium state that there will be rise in temperature from 1.7 to $4.9^{\circ} \mathrm{C}$ in winter and from 2.4 to $6.6^{\circ} \mathrm{C}$ at the end of 2100 in relation to the end of 2000 (Ntegeka 2006). The change in rainfall as projected previously shows a rise from $6 \%$ to $23 \%$ for winter and a drop of up to $50 \%$ for summer until the end of 2100 (Ypersele 2004). A resulting intensified global and regional hydrologic cycle is expected by these predicted temperature rises (Huntington 2006). Urbanization, on the other hand, causes dramatic environmental changes as vegetation is removed, soils become covered by impervious surfaces and streams are replaced by pipes which are illustrated by rapid flow responses and high peak flows following even modest rainfalls due to decreased infiltration and increased runoff (Semadeni-Davies et al. 2008, White et al. 2006). Increase in runoff occurs in proportion to the cover of impervious surface in a catchment (Arnold et al. 1996) which increases peak discharges and flood extents. Land cover change, especially urbanization, within a watershed is also recognized as an important factor affecting runoff (Chang 2007), and it is possible that the transformation of land across the globe could have a greater influence on runoff than climate change (Vorosmarty et al. 2000). Urbanization, as well as changes in land uses and vegetation, within a watershed may further exacerbate the effect of climate change on runoff from the watershed (Georgiyevsky and Shiklomanov 2003). Until now, climate change impact assessment for urban areas has been focused on flood risk from river systems alone rather than storm and wastewater drainage (Semadeni-Davies et al. 2008). In the city of Turnhout in Belgium, the urban development within the city and modifications of the riverbed over the years caused increasingly frequent and harmful flood events affecting agricultural lands downstream. Any further expansion of urban fabric together with climate change impact may aggravate the situation beyond the existing water management capacity.

\section{General Aims of the Study}

General aim of this study is to compare the effect of urbanization and climate change on the river flow causing severe urban flooding.

Specifically it can be summarized as:

i. Hydrological modelling for the sub-catchments using NAM (Nedbør-AfstrømningsModel), a lumped conceptual hydrological model;

ii. Development, calibration and validation of a one-dimensional hydrodynamic model for the two rivers, the Aa and the Visbeek, using MIKE 11 hydrodynamic software;

iii. Simulation of an existing Sewer System Model 'Info Works-CS' to generate urban drainage scenarios; and

iv. Simulation of validated one-dimensional hydrodynamic model for the river network and generation of flood maps using MIKE 11-GIS interface. 


\section{Study Area Description}

The study focuses on the city of Turnhout in the Province of Antwerp, North of Flanders in Belgium. The city is located on a plateau between two small rivers, the Aa and the Visbeek, belonging to the KleineNete basin. The Aa river has a length of $19 \mathrm{~km}$ with a contributing area of $52.52 \mathrm{~km}^{2}$ while the Visbeek river has a length of $11 \mathrm{~km}$ with a contributing area of $19.19 \mathrm{~km}^{2}$. The study area has been displayed in Figure 1.

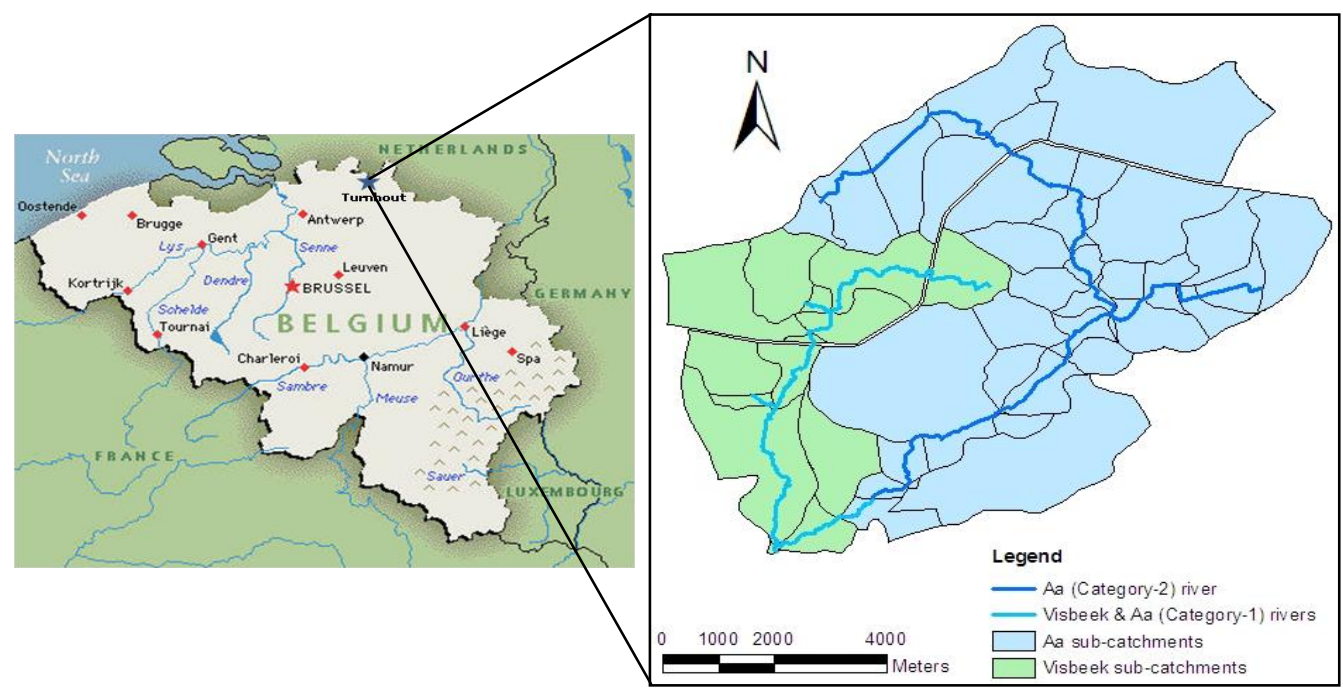

Figure 1: Location of the city of Turnhout in Belgium, the sub-catchments and the rivers

\section{Methodology}

\section{Data Collection}

In comparing the flood risks due to urbanization and climate change the study aimed at developing a fully hydrodynamic model MIKE 11, but data collection had been a hard task from the very beginning. The Water Authority of the Province of Antwerp developed a model for the river network consisting of the Aa and the Visbeek Rivers using Info Works RS model which is a dynamic modelling software for open channels, culverts, floodplains, embankments and hydraulic structures. Info Works RS provides a powerful tool to import, clean up and store survey and time-series data, build detailed and accurate models, analyze model results and present outputs in engineering report quality formats (Wallingford Software 2009). So, all the data on river geometry and network; hydraulic structures and time series of boundary conditions were readily extracted from the existing Info Works RS model. The hydrological data such as rainfall series were obtained from HYDRONET database operated by Vlaamse Milieu Maatschappij (VMM), while evapotranspiration data were obtained from Royal Meteorological Institute (KMI) for the Uccle station in Belgium.

\section{Hydrological Modelling Using NAM}

NAM is the abbreviation of the Danish "Nedbør-Afstrømnings-Model", meaning precipitation-runoff-model which was originally developed by the Department of Hydrodynamics and Water Resources at the Technical University of Denmark. NAM is a lumped conceptual hydrological model, describing the hydrological system taking into account four linear reservoirs in series. The NAM hydrological model simulates the rainfall-runoff processes occurring at the catchment scale. NAM forms part of the rainfall- 
runoff (RR) module of the MIKE 11 river modelling system (DHI 2008). NAM includes parameters of an empirical and conceptual nature. In NAM model both manual and auto calibration methods are included for adjusting the parameters. The manual calibration is a method of trial and error which usually starts by adjusting the water balance in the system. While in automatic calibration, the calibration objectives have to be formulated as numerical goodness-of fit measures that are optimized automatically (DHI 2008). Four numerical performance measures are used for the four objective functions included in the model. In the study the basic three components were considered since there was negligible occurrence of snow in the area. The input data for the modelling process was meteorological daily data of precipitation and potential evapotranspiration. The period from 1st January 1997 to $31^{\text {st }}$ December 2001 was considered for calibration and 1st January 1993 to 31st December 1996 for validation.

\section{Hydrodynamic Modelling Using MIKE 11}

MIKE 11 (DHI, 2008) is one of the examples of one dimensional hydrodynamic software models. The model solves the Saint-Venant equations for shallow water waves in open channel using a finite-difference scheme. The model requires data on river geometry (crosssections perpendicular to the flow direction), the stream bed resistance factors (Manning coefficient) and the time series of upstream and downstream flow discharge or stage height boundary conditions. So, for each grid point (cross-section) average water depth and velocity is then calculated using the finite-difference approximation (Timbe 2007).

In this study 1D hydrodynamic MIKE 11 (DHI 2008) model was used and the calibration and validation of the model was performed using the river flow data obtained from the Province of Antwerp. Flood maps were derived from the simulation of MIKE 11-GIS motel which illustrate the flood related variables such as water depth and inundation areas.

\section{Urban Sewer System Modelling Using InfoWorks-CS}

InfoWorks CS is a comprehensive, easy-to-use and flexible system for the management of urban drainage network models, including storm water or wastewater drainage systems or a combined storm water and wastewater system. A network contains all the information needed to describe the drainage system. Each network is modelled as a collection of sub-catchment areas that drain to nodes (manholes or grade breaks) which are joined by links (conduits, pumps etc.) (Wallingford Software 2009). For this study, an existing model for the collector system, Info Works CS, developed and validated by Province of Antwerp. The model includes the present sewer system, consisting of a combined (rain+waste) water system and the new parallel (piped) rainwater collector system. The validated InfoWorks-CS model was simulated to generate urban runoff for different storm events in both sub-catchments, i.e. Aa and Visbeek.

\section{Urbanization and Climate Scenario Development}

The main purpose of calibrating the NAM model was to investigate the possible changes in the discharge of the rivers due to urbanization and climate change. Simulation of Info Works-CS model generated urban runoff for different storm events in both subcatchments, i.e. Aa and Visbeek.

The climate change scenarios were obtained using the perturbation algorithm developed in the CCI-HYDR project at Hydraulics Laboratory of Katholieke University of Leuven for facilitating the climate change impact assessment in Belgium. The algorithm imparts a perturbation to an observed series to generate future time series. In this tool the observed time series are perturbed on the basis of four SRES scenarios (A1B, A2, B1 and B2) which 
were based on statistical analysis and statistical downscaling of a large number of climate model simulations (Ntegeka and Willems 2008). So, the perturbation of rainfall from the Turnhout station and evapotranpiration from the Uccle station was performed by using this CCI-HYDR Perturbation Tool to generate the future time series of the same for 2100s. These time series were then used as the input in the calibrated hydrological model NAM to generate the rainfall-runoff from the sub-catchments under future climate conditions. The future urbanization scenarios were obtained from the simulation of Info Works-CS model using perturbed rainfall events. These scenarios represent the urban runoffs from different sources in the city. The simulation results from NAM and Info Works-CS were statistically processed (extreme value analysis) and compared with the current values to assess the change in only the high peak values for the analysis of flood frequency towards the end.

\section{Generation of Composite Hydrograph}

Composite hydrograph is a synthetic hydrograph which refers to an average discharge corresponding to a specific return period for all the durations that are considered centrally in the hydrograph (Vaes et al. 2000). Firstly, the rainfall-runoff discharges from the hydrological model were analyzed for the flood frequency distributions with different aggregation-levels which vary from 1 hour to 3 days. The composite hydrographs for each sub-catchment and boundary condition were then generated using extreme value analysis applied to time series of rainfall-runoff discharges. These distributions were summarized in the form of 'discharge/duration/frequency' (QDF) relationships and more advanced, in the form of 'composite hydrographs'.

\section{REsults AND Discussions}

\section{Hydrological Modelling Using NAM}

The final simulation result of Aa sub-catchment has the following optimum values for the nine NAM parameters as presented in Table 1. Description of the parameters with their usual range can be found in the reference manual of MIKE 11 (DHI 2008).

\section{Table 1}

Summary of calibrated NAM model parameters for Aa sub-catchment

\begin{tabular}{|l|l|l|l|l|l|l|l|l|l|}
\hline Parameters & $\mathbf{U}_{\max }$ & $\mathbf{L}_{\max }$ & $\mathbf{C Q}_{\mathrm{OF}}$ & CK $_{\mathrm{IF}}$ & $\mathbf{C K}_{1,2}$ & TOF & TIF & TG & CK $_{\text {BF }}$ \\
\hline & $(\mathrm{mm})$ & $(\mathrm{mm})$ & $(-)$ & (hours) & (hours) & $(-)$ & $(-)$ & $(-)$ & (hours) \\
\hline Values & $\mathbf{1 9}$ & $\mathbf{1 1 6}$ & $\mathbf{0 . 9 0}$ & $\mathbf{6 8 1}$ & $\mathbf{4 4}$ & $\mathbf{0 . 0 0 6}$ & $\mathbf{0 . 9 2}$ & $\mathbf{0 . 1 5}$ & $\mathbf{3 6 1 0}$ \\
\hline
\end{tabular}

The optimum values of these parameters lie between the range of values as recommended by the NAM manual (DHI 2008). CQOF and CK1,2 values are reasonable according to the characteristics of the catchment. Since the size of the catchment is small, the fast response to the rainfall input is expected. Besides, since the area is highly urbanized leading to more impervious area, the infiltration capacity of the area is expected to be lower and in turn higher proportion of the excess rainfall goes to the overland flow component.

The reliability of the NAM was evaluated based on the Nash-Sutcliffe Efficiency (NSE) which evaluates the percentage of accuracy or goodness of the simulated values with respect to their observed values. The NSE obtained from the final simulation result is 0.61 . The discrepancy of water balance is $-2.1 \%$. The graphical comparison of simulated and observed flow for the whole calibration period is presented in Figure 2 which represents a well calibrated model. Further the model was validated resulting in an NSE value of 0.60 . 


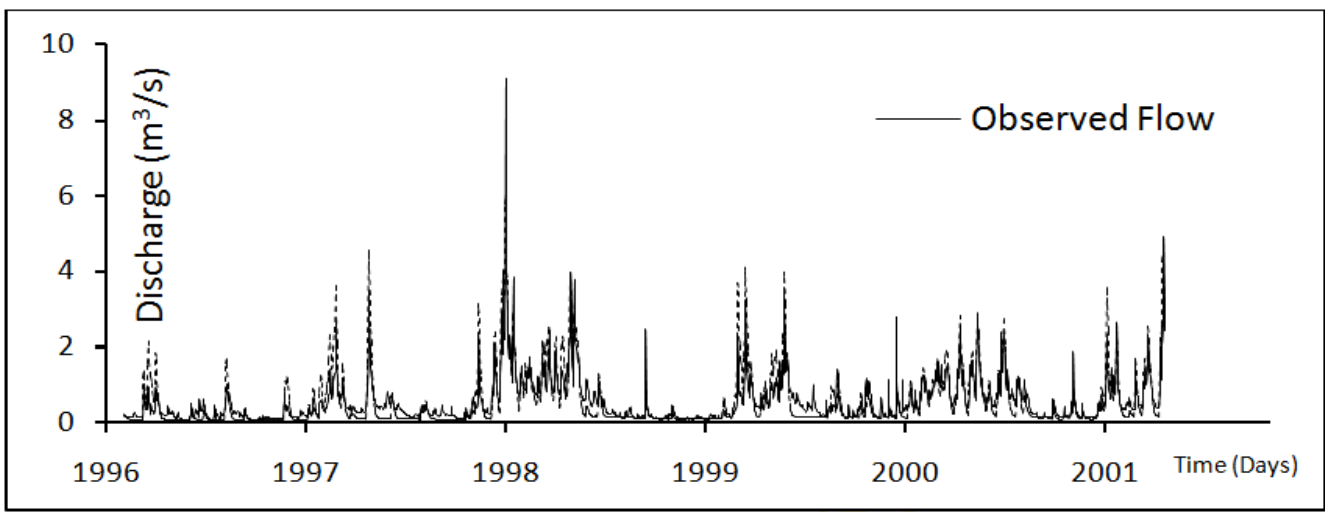

Figure 2: Calibration result of NAM for the period 1997-2001

\section{Calibration and Validation of MIKE 11 Model}

Initially we had very limited data for the calibration and validation of MIKE 11 model. We had very short-term series of discharge, maximum and minimum water levels in the flood plains obtained from the Water Management Division of the Province of Antwerp, Belgium measured during their campaign. So, the model calibration and validation were performed in the following ways. Figure 3 presents comparison of water levels between MIKE 11 and available data at the downstream of different hydraulic structures for the period 02/12/1996 04:00:00 to 17/12/1996 09:00:00.

From the results is can be seen that there is good match between the water levels being compared with some systematic underestimation and overestimation at some structures which can be overcome with further calibration effort.
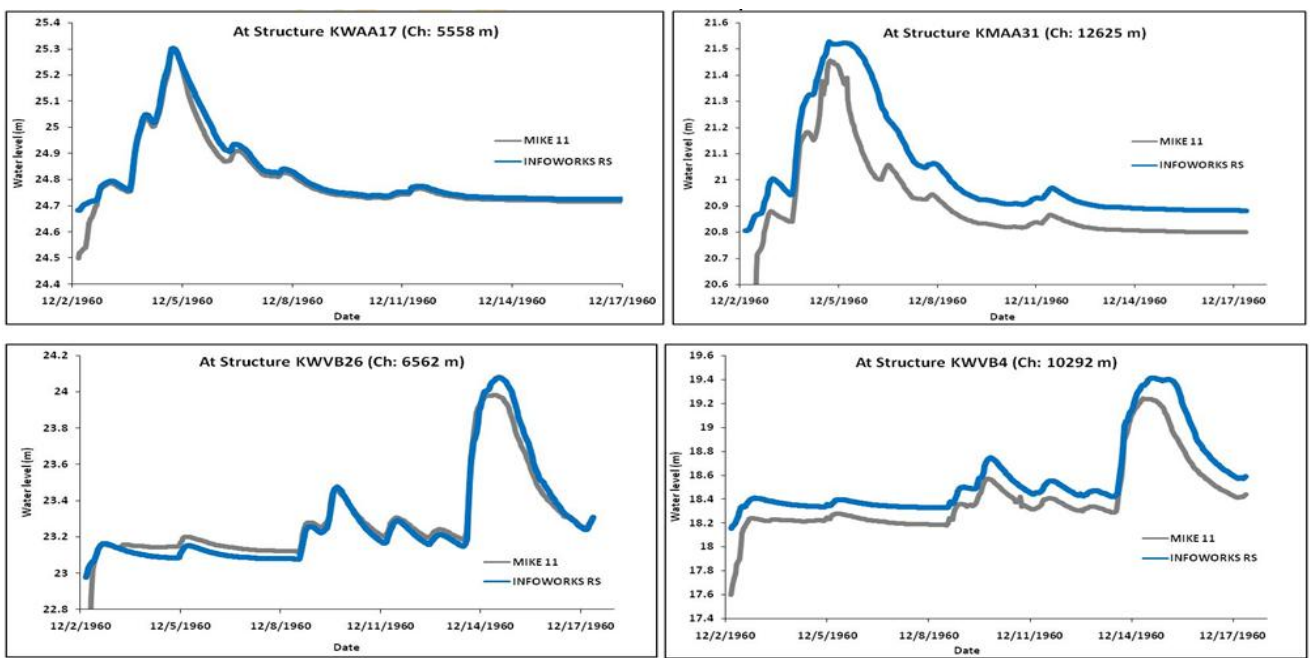

Figure 3: Comparison of water levels between MIKE 11 and available data at different structures along the rivers for the calibration period

Similar good match between the discharges can be observed with some discrepancies in the peak which can be improved by further calibration efforts (setting different Manning's n for different river reaches). The Manning's $\mathrm{n}$ for the floodplains was calibrated by achieving a good agreement between the maximum and minimum water levels in the floodplains during 
the flooding conditions. The simulated average maximum water level in the floodplains from MIKE 11 is $22.80 \mathrm{~m}$ as compared to average value of $23.05 \mathrm{~m}$ measured during the campaign with an average variation in maximum water levels by $1.16 \%$ and by $0.98 \%$ in minimum water levels.The simulated rainfall-runoff from NAM was used to validate the MIKE 11 model for the period of 25 October 1998-7 November 1998. The simulated average maximum water level in the floodplains from MIKE 11 is $22.71 \mathrm{~m}$ as compared to $22.89 \mathrm{~m}$ as obtained from the Water Management Division of the Province of Antwerp with an average variation in the maximum water levels by $0.71 \%$ and by $2.47 \%$ in the minimum water levels. The model performance was also satisfactory for water levels in all the floodplains with an R value of 0.99 and a NSE value of 0.97 for the validation period.

\section{Impact of Urban Runoff and Climate Change on Peak Flows}

Urban runoff from eleven collection points around the city was considered to assess their impact on peak runoff from two sub-catchments. In order to assess this impact the simulated runoff results of NAM were considered for subsequent extreme value analysis. On the other hand, it is expected that the risk associated with flooding is higher in the high scenario; the climate change impact analysis was based on the high scenario which represents the most pessimistic scenario. The extreme value analysis revealed that there was an average increase of $36 \%$ in the peak runoff from two sub-catchments due to these urban runoffs where as an average increase of peak runoff by $23 \%$ for higher return periods, while an average decrease of relatively lower peak runoff by $19 \%$ for lower return periods as compared to the current conditions.

Since the runoff is more sensitive to climate change than to urban runoff (i.e. urbanization), the situation might deteriorate further if urban runoffs from the city arecombined with climate change. The increase in peak runoff becomes higher when the impact of both the variables is taken into account concurrently than they are considered individually. The average increase of peak runoff due to combined impact is about $56 \%$ with comparison to the current trend as shown in Figure 4. The relative impact of urbanization and climate change both individually and combined is presented in Figure 4 .

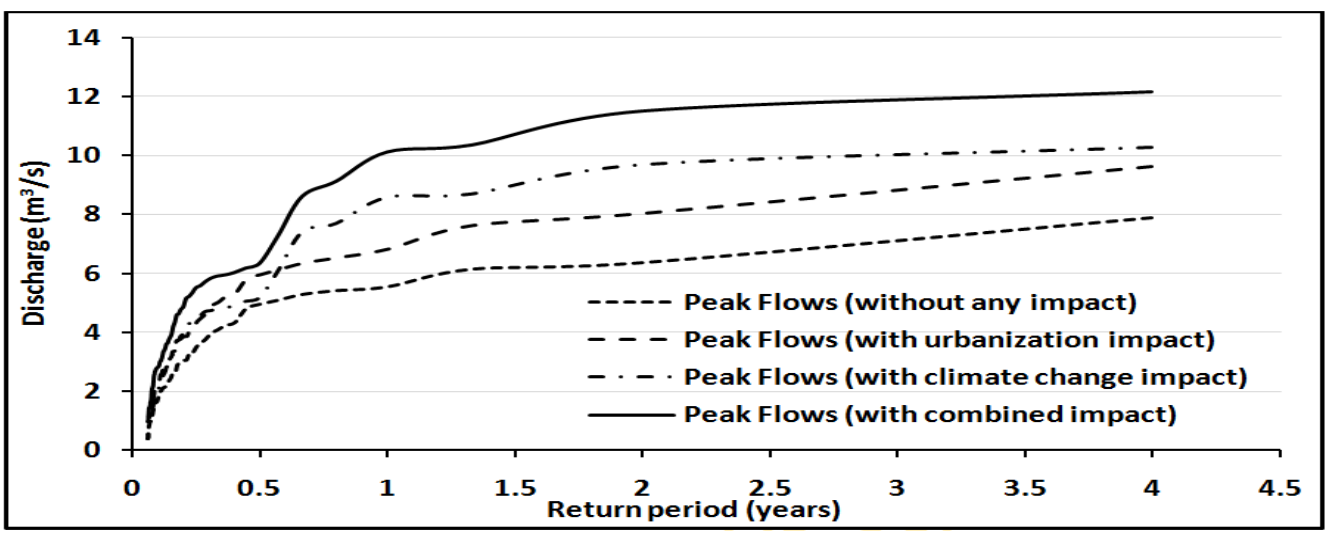

Figure 4: Relative effect of urbanization and climate change 'high' scenario both alone and together on peak runoff from two sub-catchments

\section{Impact of Urbanization and Climate Change on Urban Flooding}

The relationships between extent of flooding and return period are important to understand the floodplain behavior in response to flood events which provide very useful information for flood control measurements and planning of the floodplains. The 
relationships between the volume of flooding water and return periods are also useful for the design of adaptation measures to store urban runoff coming from the city to avoid flooding in the lower valley of the rivers. These relationships allow water managers to decide what adaptive measures are to be implemented for the vulnerable areas to overcome the adverse situation of flooding. Urban runoffs might aggravate the situation of flooding in the downstream of the valley as they cause further extension of flooding areas, increasing by $5.36 \%$ and $6.1 \%$ in all the entire floodplain while $22.31 \%$ and $25.8 \%$ in the lower valley for a return period of 50 and 100 years respectively (Figure 5).

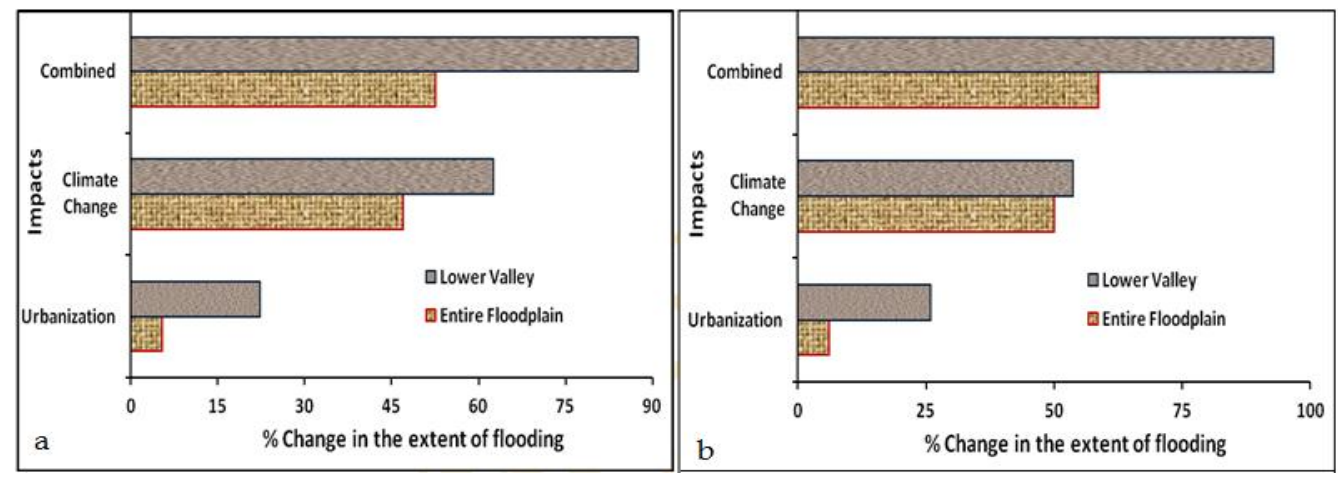

Figure 5: Change in the extent of flooding as compared to the normal situation without any impact (Return period $=$ a. 50 and b. 100 years)

The results in Figure 5 show that the further extension of flooding area could be quite frequent under future climatic conditions. The climate change alone may aggravate the situation even worse than urbanization could cause individually, although this issue has not been considered by the water managers in the city. The flooding area in the entire floodplain increases by $47.0 \%$ and $50.0 \%$ due to climate change in comparison to $5.4 \%$ and $6.1 \%$ due to urbanization for return period of 50 years and 100 years respectively. The situation might be even worse in the lower valley of the rivers as the flooding areas are further extended due to climate change by higher percentages as depicted in Figure6.

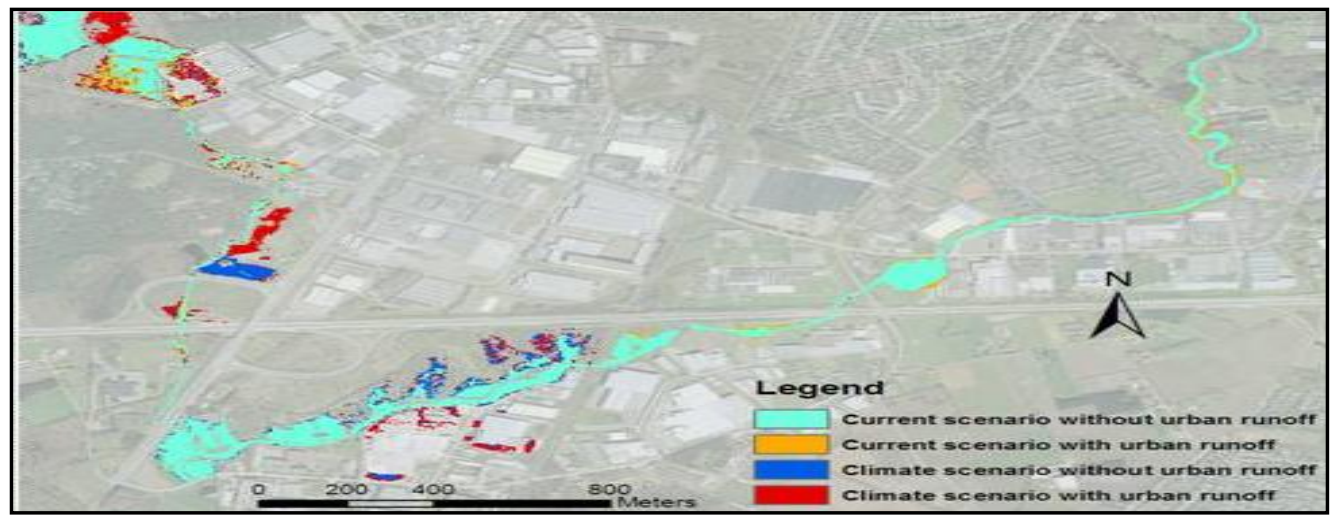

Figure6: Flood maps showing the impacts of urbanization and climate change for a return period of 100 years

The results in Figure 7 also provide important information on volume of water in the flooding areas which could be utilized to design appropriate management alternative to overcome any future water hazard in a holistic way. 


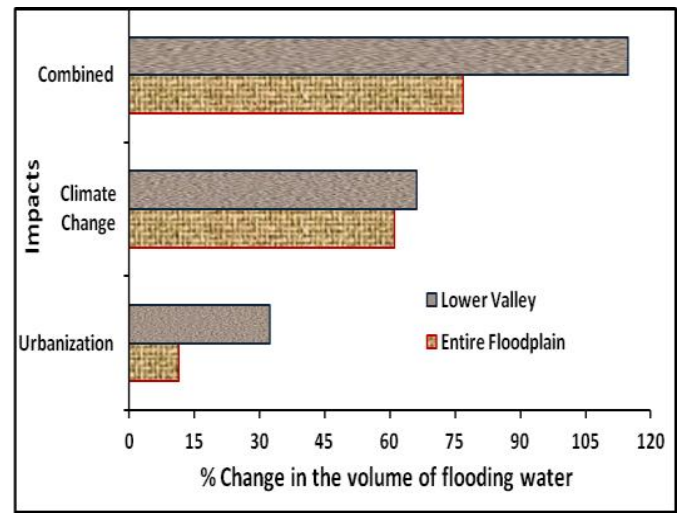

a.

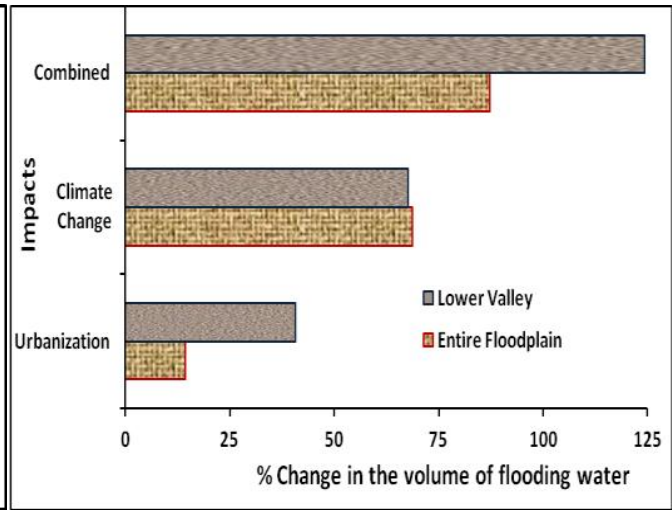

b.

Figure 7: Change in the volume of flooding water as compared to the normal situation without any impact (Return period $=$ a. 50 and $b .100$ years)

An amplification of both inundation area and volume of flooding water resulting from intensified runoff from the sub-catchments is caused from the combined impact of urbanization and climate change, when compared with only climate change or urbanization. For return period of 100 years, the inundation area in the entire floodplain increases from the current condition by $58.7 \%$ due to combined impact with comparison to $6.1 \%$ due to only urbanization and $50 \%$ due to only climate change.

\section{CONCLUSION}

The extreme value analysis reveals that the return period of a flood event will be decreased causing the event to be more frequent in future with comparison to the current frequency of occurrence due to impact of urbanization and climate change. Impact of climate change is more intensified than that of urbanization while the combined impact is the most. This trend might be useful for the city water authority to search for the options which must be designed appropriately to combat this exacerbating impact that has not yet been taken into consideration in any of the alternatives proposed hitherto. The intensification due to combined impact of urbanization and climate change might cause more frequent and higher floods than the one prevailing at present and could be considered in selecting an appropriate management alternative to overcome the flooding problem. The flooding situation becomes exacerbated in the downstream of the city, i.e. the lower valley when the combined impact of climate change and urbanization is taken into account. It was observed during the detailed study by the Province of Antwerp that the agricultural lands in the lower valley were mainly affected by the frequent flooding events and the flooding areas noticed in the present study are consistent with the existing situation with all the scenarios analyzed depicting the real scenario regarding urban flood risks in Turnhout.

\section{REFERENCES}

Chang, H. J. (2007) Comparative stream flow characteristics in urbanizing basins in the Portland Metropolitan Area, Oregon, USA. Hydrological Processes 21(2), 211-222.

DHI. (2008) MIKE 11 A modelling system for rivers and channels, Reference and User Manual. DHI Water \& Environment, Hørsholm, Denmark.

Franczyk, J. and Chang, H. (2009) The effects of climate change and urbanization on the runoff of the Rock Creek basin in the Portland metropolitan area, Oregon, USA. Hydrological Processes 23, 805-815. 
Georgiyevsky, V. and Shiklomanov I. (2003) In World Water Resources at the Beginning of the 21st Century. Cambridge University Press, Cambridge.

Huntington, T. G. (2006) Evidence for intensification of the global water cycle: Review and synthesis. Journal of Hydrology 319(1-4), 83-95.

Ntegeka, V. (2006) An empirical statistical approach to climate change impact on hydroclimatic extremes. Master thesis, K. U. Leuven and V.U.B., Belgium.

Ntegeka, V. and Willems, P. (2008) CCI-HYDR Perturbation Tool: a climate change tool for generating perturbed time series for the Belgian climate. Catholic University of Leuven \& Royal Meteorological Institute of Belgium, Manual, December Version, 1-7.

Semadeni-Davies, A., Hernebring, C. et al. (2008) The impacts of climate change and urbanisation on drainage in Helsingborg, Sweden: Combined sewer system. Journal of Hydrology 350(1-2), $100-$ 113.

Semadeni-Davies, A., Hernebring, C. et al. (2008) The impacts of climate change and urbanisation on drainage in Helsingborg, Sweden: Suburban storm water. Journal of Hydrology 350(1-2), 114125.

Timbe, L. (2007) River flooding analysis using quasi-2D hydraulic modelling and geospatial data. $\mathrm{PhD}$ thesis, Catholic University of Leuven, Faculty of Engineering, Leuven, Belgium.

$\mathrm{Tu}$, J. (2009) Combined impact of climate and land use changes on streamflow and water quality in eastern Massachusetts, USA. Journal of Hydrology 379(3-4), 268-283.

Vaes, G., Willems, P. and Berlamont, J. (2000) Selecetion and composition of representative hydrographs for the river design calculations. In: ERB 2000, Int. Coference on 'Monitoring and modelling catchment water quantity and quality' (ERB), 27-29 September 2000 Gent, 53-55.

Vorosmarty, C. J., P. Green, et al. (2000) Global water resources: Vulnerability from climate change acid population growth. Science 289(5477), 284-288.

Wallingford. (2009) InfoWorks RS Help Documaentation, Version 10.5, Wallingford Software, United Kingdom.

White, M.D. and Greer, K.A. (2006) The effects of watershed urbanization on the stream hydrology nd riparian vegetation of Los Peñasquitos Creek, California. Landscape and Urban Planning 74, $125-138$.

Yperesele, V. (2004) Impacts of climate change in Belgium. Report commissioned by Greenpeace. 